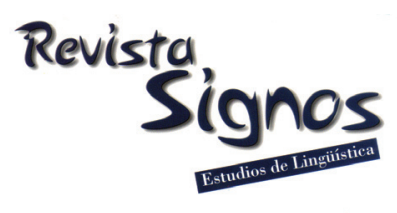

\title{
Posicionamientos discursivos en la construcción de identidad étnica en adolescentes mapuches de Temuco y Santiago ${ }^{1}$
}

\section{Discursive positioning in the construction of ethnic identity among mapuche adolescents in Temuco and Santiago language}

\author{
María Eugenia Merino \\ Universidad Católica de Temuco \\ Chile \\ mmerino@uct.cl
}

\author{
Ximena Tocornal \\ Universidad Diego Portales \\ Chile \\ ximenatocornal@mail.udp.cl
}

Recibido: 1-II-2011 / Aceptado: 9-XI-2011

\section{Resumen}

Los estudios sobre identidad étnica mapuche desde una perspectiva del análisis del discurso son aún bastante escasos. Entre ellos destacamos el de Merino, Mellor, Saiz y Quilaqueo (2009) sobre los efectos psicosociales que las experiencias de discriminación generan en los mapuches en Chile. Dicho estudio mostró que la discriminación puede generar efectos negativos y positivos de largo plazo en la vida de las personas, destacándose entre estos últimos la reafirmación étnica y el incremento de la autoestima, proceso que se inicia en el período de la adolescencia. El presente artículo describe las principales modalidades de posicionamiento discursivo que realizan los adolescentes mapuches de Temuco y Santiago respecto de su identidad étnica y las estrategias discursivas más frecuentes que utilizan para tales acciones. El análisis desde el enfoque de la Psicología Discursiva (Edwards \& Potter, 1992) releva las principales categorizaciones, descripciones y atribuciones que los jóvenes asignan a la cultura mapuche para resolver la tensión dilemática de posicionarse frente a su identificación étnica en contextos urbanos. Los resultados muestran que la construcción de identidad mapuche se realiza posicionándose como miembro activo o pasivo de la cultura, y donde el apellido, la lengua mapuche y la participación en ritos y ceremonias culturales constituyen elementos esenciales del ser mapuche.

Palabras Clave: Identidad étnica, posicionamiento discursivo, adolescentes mapuches urbanos. 


\begin{abstract}
Studies on mapuche ethnic identity from a discursive perspective are still scarce in Chile. One of the relevant works on this area is that of Merino, Mellor, Saiz and Quilaqueo (2009) on the psychosocial effects of discrimination on mapuche individuals' lives which revealed that there may be negative and also positive effects. Among the latter we highlight ethnic reaffirmation and the increase of self esteem, a process that starts within adolescence. This article describes the main discursive positionings that mapuche adolescents from Santiago and Temuco construct when they talk about their ethnic identity, and also the discursive strategies used for such purpose. The analysis based on Discursive Psychology (Edwards \& Potter, 1992) reveals the essential categorizations, descriptions and attributions that youngsters hold to solve the dilemmatic tension of facing their ethnic identification in urban contexts. The main findings show that, ethnic identity is made through positioning as active or passive member of the culture, where the mapuche name, speaking the indigenous language and active participation in cultural rites are deployed as essentials of the mapuche being.
\end{abstract}

Key Words: Ethnic identity, discursive positioning, urban mapuche adolescents.

\title{
INTRODUCCIÓN
}

El interés por las identidades culturales se ha acrecentado en las últimas décadas debido por una parte a los efectos de la globalización y el surgimiento de nuevas tecnologías de la comunicación, y por otra, al reciente fenómeno de reivindicación de las culturas locales y los derechos de los pueblos originarios. En este contexto la reivindicación de las identidades constituye uno de los fenómenos contemporáneos más evidentes y de mayor interés social y político de nuestros tiempos. Ello se hace más patente en contextos de relaciones interétnicas e interculturales asimétricas donde las prácticas de dominación cultural hacia minorías indígenas generan diversos tipos de conflicto entre los grupos mayoritarios y las culturas indígenas, como es el caso del pueblo mapuche en Chile. En este contexto la identidad y la identificación étnica se constituyen en procesos dilemáticos atravesados por relaciones caracterizadas por el prejuicio y la discriminación.

Lo anterior ha sido corroborado desde variadas perspectivas disciplinarias. Por ejemplo en el ámbito educativo (Tripailaf, 1969; Bascur, 1998; Cerda \& Toledo, 2000; Abarca, 2002), desde los estudios antropológicos (Cantoni, 1978; Durán, 1984; Vergara \& Foerster, 2002; Gunderman, 2006; Foerster \& Montecino, 2007), desde la psicología (Saiz \& Gempp, 2001; Saiz, 2002), desde la historia (Bengoa, 2002; Gundermann, Vergara \& Foerster, 2005; Curivil, 2007), y también desde la perspectiva de género (Montecino \& Willson, 1993; Cuminao, 1998; Fernández, 2006). 
Sin embargo, desde una perspectiva centrada en el discurso los estudios sobre identidad étnica mapuche son aún escasos. Se destaca el trabajo de Merino et al. (2009)² que demostraron que las experiencias de discriminación generan en los mapuches efectos psicosociales inmediatos y de largo plazo. Los primeros son experimentados en el momento del evento discriminatorio expresándose mediante emociones como tristeza y vergüenza, y a través de estilos de afrontamiento como son respuestas defensivas, auto-controladas o de confrontación.

Un interesante hallazgo de este estudio plantea que las experiencias de discriminación generan reafirmación étnica e incremento de la autoestima, ello como resultado de la acción de la familia de reafirmar y educar a los niños y jóvenes para enfrentar positivamente la discriminación. Estos estudios constataron además que los efectos movilizadores de identificación étnica se inician en el período de la adolescencia (Mellor, Merino, Saiz \& Quilaqueo, 2009, Merino et al., 2009). Fueron precisamente estos hallazgos los que motivaron nuestro interés en indagar cómo los adolescentes mapuches urbanos de Temuco y Santiago construyen discursivamente su identidad étnica ${ }^{3}$.

En consecuencia, el objetivo del presente trabajo es describir las principales modalidades de posicionamiento que realizan los adolescentes mapuches de Temuco y Santiago respecto de su identidad étnica y las estrategias discursivas más frecuentes utilizadas para tales acciones. Para ello se describe la construcción discursiva que los adolescentes realizan de su identificación étnica en tanto jóvenes urbanos y miembros de la sociedad chilena. El enfoque teórico metodológico lo aporta la psicología discursiva (Potter \& Wetherell, 1987; Edwards \& Potter, 1992; Potter \& Edwards, 2001) por su orientación hacia la acción, la situación y la construcción de identidades.

\section{Marco teórico}

La 'adolescencia' constituye la transición entre el infante y el adulto experimentado mediante cambios de cuerpo y mente, y también en la forma cómo el joven evalúa y se relaciona con su entorno. Se trata de un período extenso que abarca entre los $10 \mathrm{y}$ los 20 años (Organización Mundial de la Salud, 2011). No obstante, para efectos de nuestro estudio, nos focalizamos en la 'adolescencia media', comprendida entre los 15 y los 20 años que es donde el joven desarrolla su búsqueda de identidad (Vaughan \& Hogg, 2002). En tanto, la identidad étnica constituye el sentimiento subjetivo de pertenecer a un grupo sobre la base de valores y creencias compartidas (Phinney, 1990).

En América Latina se cuenta con una profusa literatura sobre identidad étnica en contextos de dominación (Bartolomé, 1987; Bonfil Batalla, 1987; Smith, 2002; entre otros). Particularmente importante para nuestro estudio son los hallazgos de Planas (2007) que caracteriza el proceso de construcción de identidad étnica de los migrantes indígenas en el Cuzco. Uno de los rasgos definitorios es el sentido de pertenencia 
étnica que se vincula con la comunidad de origen, y cuando se reside en la ciudad puede realizarse a través de la recreación de los vínculos comunitarios en contexto urbano. Segundo, la identidad étnica se construye mediante un proceso contradictorio de afirmación y negación en una relación dialéctica entre la categorización ejercida desde el 'otro' no indígena y la autoadscripción. Finalmente, la etnicidad es vivida de modo distinto por los hijos, si bien los jóvenes y los hijos de migrantes viven en contextos de mayor interculturalidad, ello no implica una ruptura total con la cultura de sus padres. Los vínculos más importantes parecen estar centrados en la valoración de sus orígenes, el vínculo con las comunidades de nacimiento y la vigencia de ciertas costumbres familiares como su comida tradicional.

Del mismo modo, se destacan los aportes de Albó (2005) que conceptualiza los grupos étnico-culturales con particular referencia al contraste entre indígenas y no indígenas en la realidad boliviana. Asimismo, aborda las problemáticas de las identidades étnicas y culturales, la ciudadanía y los derechos de los quechuas y aymaras al interior de la nación boliviana, y plantea que ambas identidades se enfrentan a diversas valoraciones sociales y autovaloraciones que obligan a desarrollar estrategias, referentes, símbolos y argumentos para caracterizar la especificidad del pueblo boliviano.

Para abordar el análisis del discurso de cómo las propias minorías étnicas narran su identidad, y en lo específico cómo los jóvenes mapuches de Chile construyen su identificación étnica a través de su discurso oral, la psicología discursiva (Potter \& Wetherell, 1987; Edwards \& Potter, 1992; Potter \& Edwards, 2001) se constituye en un marco teórico metodológico consistente. Ello debido a que se trata de un paradigma epistémico de enfoque socioconstructivista (Zimmermann \& Wieder, 1970; Berger \& Luckmann, 1991; Bauman, 2000; Hall, 2001) que articula teorías y métodos postestructuralistas del lenguaje de manera integrada para explicar cómo el hablante construye y modifica realidades mediante su discurso desde el análisis del discurso y particularmente del análisis de la conversación (Sacks, 1972) y teniendo como base las teorías de Wittgenstein (1953), Austin (1961) y Searle (1979).

Los principios fundamentales que subyacen a la psicología discursiva son su orientación hacia la acción, la situación y la construcción. Las acciones forman parte de prácticas más amplias, se despliegan en diferentes tipos de contextos que las regulan y contribuyen a la realización de los diferentes tipos de contextos en que se realizan. Al ser las acciones situadas, el discurso es concebido, por una parte como 'construido' desde una variedad de recursos como las palabras, categorías, lugares comunes retóricos y repertorios interpretativos; y por otra, como 'constructor' de diferentes versiones del mundo, incluyendo versiones de acciones, eventos, historias, estructuras sociales y organizaciones, características psicológicas y experiencias fenomenológicas. 
Desde este enfoque teórico metodológico el posicionamiento es entendido como la construcción discursiva de historias personales que hacen que las acciones de una persona sean inteligibles y relativamente determinadas como actos sociales y dentro de los cuales los miembros de la conversación toman ubicaciones específicas (Harré \& van Langenhove, 1999). Posicionarse en un evento discursivo significa que el hablante selecciona de una serie de posibilidades una acción en particular de acuerdo al contexto, la situación y la relación de los participantes. Por ejemplo, al decir ‘ ¿dónde está la sal?' un hablante se puede posicionar como preguntando dónde se encuentra la sal (posicionamiento de primer orden) y su interlocutor se posicionará de acuerdo a la interpretación que le otorgue a la pregunta del hablante, pudiendo decir por ejemplo '¡en la cocina!', 'yo te la traigo’, ‘'búscala tú, no seas flojo!'. En consecuencia, los posicionamientos generan circuitos interactivos de variados efectos entre los participantes de un evento discursivo. Para posicionarse el hablante puede manejar su argumento mediante variadas estrategias discursivas, dependiendo de su personal interés en el tema y las características del evento comunicativo ${ }^{4}$.

Para la psicología discursiva, la identidad en tanto objeto de estudio no habita en las mentes sino en el ámbito público y es analizable desde el discurso. De este modo la identidad es realizada, construida y producida momento a momento en la conversación cotidiana. Los enfoques discursivos de la identidad en tanto fenómeno público y discursivo permiten explicar por qué las personas orientan sus relatos de manera consistente acerca de ellos y de otros, lo que socava la tesis de que la identidad es un elemento homogéneo y fijo. En consecuencia, la identidad se entiende como múltiple y dilemática más que unitaria y coherente, siendo contingente a las condiciones locales de la interacción y del contexto, destacándose la variabilidad como un rasgo del discurso que responde a la noción postmoderna de identidades múltiples y cambiantes que se despliegan en el habla (Potter \& Wetherell, 1987).

Un constructo básico para analizar la identidad son los procesos de categorización, debido a que los hablantes son conceptualizados como jugando roles dentro de una categoría con características o rasgos asociados. Las categorías que definen la identidad de las personas son entendidas como localmente ocasionadas y hechas relevantes a través de orientaciones específicas desplegadas por los interactuantes en contextos interaccionales y negociados con sus interlocutores (Bauman, 2000).

El enfoque clásico de la psicología cognitiva define la identidad étnica como un sentimiento subjetivo de pertenencia a un grupo sobre la base de valores, comportamientos y creencias compartidas (Phinney, 1990), entendidas éstas como 'etnicidad', y la posesión de características físicas particulares, definidas bajo el concepto de 'raza' (Bernal, Knight, Garza, Ocampo \& Cota, 1990). Sin embargo, desde la psicología discursiva la identidad étnica es más bien un fenómeno 'a ser construido' discursivamente y al que se le da vida y se reconstruye una y otra vez según el evento de habla en que el hablante se encuentre participando (Wetherell, 2009). 
Un estudio interesante en esta línea es el de Verkuyten y de Wolf (2002) que describen cómo residentes chinos en los países bajos construyen distintas versiones de identidad al interactuar entre sí, movilizando recursos discursivos y culturales en relatos de tipo agentivo y determinístico de su identidad. La relevancia de estudios como estos reside en enfocar la identidad de minorías étnicas como un fenómeno 'a ser construido' durante el transcurso de la interacción entre miembros de una misma cultura.

\section{Metodología}

\subsection{Participantes}

La muestra total del estudio son treinta adolescentes hombres y mujeres mapuches de la ciudad de Temuco y treinta de la ciudad de Santiago ${ }^{5}$. Sin embargo, para efectos del presente artículo se seleccionaron seis entrevistas: tres de Santiago y tres de Temuco. El criterio de selección fue la posesión de al menos un apellido mapuche y estar dispuesto a participar voluntariamente en una entrevista tipo conversación. Los jóvenes provenían de liceos municipales y subvencionados, de universidades e institutos de formación técnica, y del ámbito privado del trabajo; para su contacto se utilizó la técnica de 'bola de nieve'.

\subsection{Recolección, transcripción y procesamiento de datos}

Las entrevistas semi-estructuradas, grabadas en audio y transcritas a formato digital según la simbología Jefferson (2004), se estructuraron en la modalidad de una conversación entre un entrevistador y un(a) entrevistado(a) mapuche. Ello permitió generar un compromiso mutuo entre miembros de un mismo grupo étnico en la producción de la entrevista (Wetherell \& Potter, 1992; Widdicombe \& Wooffitt, 1995). De este modo se construyó un espacio conversacional donde los temas de identidad étnica y autodefinición étnica se negociaban y desplegaban (Baker, 2000), no como un reflejo de vida e identidades que ocurren fuera de la entrevista (Miller \& Glassner, 1997), o como simples reportes de la realidad (Holstein \& Gubrium, 1995), sino más bien como un producto específico de un espacio de interacción en sí mismo (Rapley, 2001). Nuestro interés en la entrevista tipo conversación es que ella constituye un:

"evento interaccional donde los participantes profundizan en su conocimiento cultural, incluyendo su conocimiento acerca de cómo los miembros y sus categorías se expresan rutinariamente" (Baker, 1997: 131).

Es decir, las respuestas de los entrevistados son analizadas como 'relatos culturales' que reflejan los recursos normativos, categoriales y perspectivas morales de su grupo (Silverman, 2001). 
Ante la pregunta inicial del entrevistador '¿qué se siente ser mapuche en la sociedad chilena actual?' hemos identificado tres modos esenciales de posicionamiento identitario en los jóvenes: poseer al menos un apellido mapuche, hablar la lengua mapudungun y participar activamente en ritos y ceremonias mapuches.

El proceso de obtención de los resultados se realizó con el software Atlas'Ti que permitió relevar las categorías y subcategorías mediante la codificación abierta, y establecer las redes y relaciones entre ellas. El análisis del discurso se basa en la psicología discursiva que incluye recursos discursivos como atribución de categorías ${ }^{6}$, normalización ${ }^{7}$, recursos emocionales y $\operatorname{cognitivos}^{8}$ y recursos de externalización ${ }^{9}$, por ejemplo reproducción de discurso directo, formulación extrema de un caso, narración, inoculación de un argumento ${ }^{10}$ (Potter, 1996).

\section{Análisis}

Poseer un apellido mapuche constituye un rasgo identificatorio esencial para considerarse miembro de la cultura mapuche, como se observa en el joven LS de Temuco, entre las líneas 1-711.

1. E: $\quad$ Me gustaría saber un poco conocerte (.) cómo es para ti o cómo (.)

2. cómo te sientes, si te sientes un joven mapuche o como te sientes

3. ser e::::::: un joven mapuche aquí en esta sociedad chilena.

4. L: $\quad$ E::.::: bueno yo me identifico mapuche pero (.) no más que

$5 . \quad$ eso

6. E: O sea te identificas, ¿por qué te identificas como mapuche?

7. L: por el apellido no más.

LS plantea un posicionamiento pasivo respecto de su autoidentificación étnica, atribuyéndose la categoría 'mapuche' pero estableciendo el apellido como lo único que lo une con esa cultura. Mediante la frase "bueno yo me identifico mapuche pero..." (línea 4) se observa que LS inocula su argumento mediante una estrategia retórica que permite establecer límites a su autodefinición situándola en la mera 'posesión' del apellido mapuche (línea 7), lo que refuerza mediante la frase enfática adverbial "no más que eso" (líneas 4-5).

A diferencia de LS, la joven CJ también de Temuco otorga credibilidad y fuerza a su posicionamiento como mapuche, lo que realiza mediante la estrategia de reproducción de discurso directo (líneas 155-157). Ello le permite posicionar su apellido como una categoría suficiente para definirse como mapuche, aunque solo posea uno de los apellidos mapuches (líneas 156-157). Esta estrategia construye un argumento vivido y convincente dirigido al entrevistador.

150. E: porque ¿por otro lado alguien te ha dicho a:::lgo en relación a tu 
151. apellido, tu eres mapuche, no se poh?

152. C: e::: no

153. E: o: solo dentro de la familia no mah?

154. C: no es que dentro de la familia y yo siempre lo he tenido claro

155. siempre me preguntan ‘'tu apellido es mapuche?' y yo le digo 'sí,

156. Es mapuche’ y me::: ‘¿y tu segundo apellido?’ ‘No, es González

157. pero igual sigo siendo mapuche?

158. E: $\quad$ ya e:::h tu me decías que no participas en ningún grupo.

159. C: e:::h no.

SV, originalmente de Temuco pero residiendo casi un año en Santiago, desarrolla dos tipos de posicionamientos: el primero donde el apellido constituyó para ella la causa de prácticas discriminatorias en la enseñanza básica y en el liceo (líneas 51-54), nótese el uso recurrente de la expresión cognitiva "yo creo" que atribuye tentativamente una actitud discriminatoria a las preguntas de los compañeros respecto de su apellido mediante la modalización "puede ser" (línea 55).

48. E: ya, ¿y situaciones de discriminación te ha tocado::: vivir?

49. SV: $\quad$ (8 seg.) $\mathrm{m}:::$ yo creo eh::: (.)

50. E: ya sea explícitamente-

51. SV yo creo que explícitamente::: no, pero no sé el hecho de los

52. apellidos en el liceo, en el colegio tal vez, cuando más chica en realidad,

53. cuando más grande ya no, (.) que

54. molestan a veces o cuando la gente te pregunta muchas veces, o lo

55. pronuncia mal, o todas esas cosas, puede ser (.)

En el segundo posicionamiento, casi al final de la entrevista, SV tiende a presentarse más proactiva respecto de los valores de la cultura mapuche, especialmente de su transmisión a los más pequeños, ya que el poseer una identidad sólida les permitirá desarrollar una mayor autoestima (líneas 206-209).

201. E ¿y qué cosas puedes decir que falten más, mayor::

202. sensibilización o algo más concreto que se vea?

203. SV: sí, yo creo que falta un poco más de sensibilización y que:::

204. en lo concreto que tú decías, como que::: que::: lograr avances 
205. reales en eso, por ejemplo, en los niños, yo encuentro

206. fundamental, y cómo es la educación también, que::: que esta

207. identidad se:::

208. ortalezca desde que son chiquititos, puedan ser personas mucho

209. más seguras, profesionales de hecho después eh::: muy conscientes

210. $\quad$ y muy proactivos en cuanto a su pueblo (.) igual se conversaba harto

211. en el hogar (hogar mapuche) sobre eso, de que en el hogar habían

212. hartos beneficios para los chicos que estaban en la universidad que

213. era la mayoría, tenían comida, alojamiento, y todo eso eh::: por un

214. costo que era mínimo, pero también se conversaba de eso, de qué:::

215. cuántos de ahí, seguramente muy pocos iban ser::: iban como a

216. devolver a su pueblo lo que::: ellos estaban aprendiendo en ese

217. momento, entonces siempre se hablaba, siempre se conversaba,

218. que::: lo importante que era tener una identidad fuerte, para que

219. después no si tengai plata, te olvides lo que eres, de dónde vienes

220. todo lo que tuviste::: a no ser un parásito de tu apellido

221. siempre decían eso los chiquillos y las cifras también lo plantean así,

222. muy::: crudamente, porque querían::: dejar en todas las personas

223. que estábamos ahí muy marcado eso (.)

Aunque su posicionamiento respecto de su identidad se observa más proactivo (líneas 207-210) SV construye un discurso cuidadoso evitando involucrarse personalmente en los hechos que relata. Nótese el uso del reflexivo "se" que opera como una estrategia sintáctica para inocular su punto de vista ante el interlocutor. Con ello despersonaliza una postura respecto de la promoción que se hacía de fortalecer la identidad mapuche en el hogar estudiantil donde la hablante residía en Temuco. La hablante usa la metáfora "no ser parásito del apellido" para ejemplificar que no se debe utilizar el apellido para conseguir beneficios del gobierno por ser mapuche, lo que realiza a través de la estrategia de corroboración y consenso con el respaldo de cifras estadísticas (líneas 213-216 "era la mayoría").

Este posicionamiento de autocuidado de la imagen que realiza SV podría deberse al prejuicio que maneja la población global en la ciudad de Temuco respecto de que 'en 
las residencias estudiantiles mapuches se preparan para ser activistas, estimulándose la violencia como método de lucha por los derechos mapuches’.

A diferencia de SV, RS también de Santiago, se posiciona de manera más explícita respecto de su apellido, de hecho ella realiza un importante número de referencias a este a lo largo de su entrevista, contabilizándose un total de 40.

1. E: $\quad$ ya para empezar a conversar vamos a partir de una pregunta

2. general y de ahí vamos a ir abordando ciertos temas

3. RS: $\quad$ ya

4. E: ¿cómo es para ti ser una joven mapuche hoy en día acá en

$5 . \quad$ nuestra sociedad, en Chile?

6. RS: eh::: yo lo que he estudiado más o menos de los mapuches

7. son::: de sus tierras y de la ayuda que uno recibe por

8. tener::: de ser de esa cultura (.) yo me siento a ver:::

9. como una adolescente privilegiada por tener mi apellido

10. porque sé que voy a recibir más ayuda y soy más especial

11. que los demás (.) porque sabiendo que uno tiene sus

12. apellidos:::: los dos::: españoles, o cosas por el estilo

13. no significan que sean menos, pero::: para mí es especial

14. tener mi apellido (.)

15.E: $\quad$ ya, es especial (.) ¿tú eres mapuche por el lado de tu

16. mamá?

17. RS: $\quad<$ Sí

18.E: $\quad$ ya ¿y de dónde es la familia de tu mamá?

19. RS: $\quad$ de Valdivia, Corral (.)

20.E: de Corral

21. RS: $\quad$ sí

22.E: ¿y allá a quién tienes, parientes, abuelos?

23.RS: eh::: tenía a mi abuelita y mi abuelito, mi abuelita y mi

24. abuelito, pero mi abuelito murió, falleció y::: por parte

25. de él saqué su apellido (.) yo no conozco mucho de él

26. porque no lo conocí, así que no tuve esa::: esa gracia de 
27. conocerlo, pero era:::: un caballero muy bueno por lo que

28. me han dicho, que se sentía orgulloso por su apellido,

29. eh::: que se lo pasó a mi abuelita, a mi mamá, a mis

30. hermanos, que su apellido era único especial, que tenían

31. que privilegiarlo harto, cuidarlo (.)

32. E: $\quad$ ¿y tu abuelita está viva?

33. ES: Sí, mi abuelita es la que más habla de su apellido, la que

34. a veces me habla palabras y no entendemos sus nietas lo que

35. dice ( $j a, j a)$, pero ella igual se siente orgullosa que su

36. hija tengan su apellido mapuche, se siente que::: siempre lo

37. van::: a ellas son de aquí de esta raza, porque son los

38. primeros que estuvieron aquí (.) entonces se sienten bien

39. orgullosas de que sus hijas tengan los apellidos (.)

El apellido constituye para RS una forma de identificación relevante y suficiente, seleccionando de su recurso emocional una serie de expresiones psicológicas. Se siente "privilegiada" (líneas 8-9) porque podrá recibir más ayuda del gobierno y además porque se siente "especial" (líneas 10-14), sentimiento que extiende también hacia su madre y abuelos maternos que se sentían "orgullosos" de su apellido (línea 28, $35,39)$ y consideraban que su apellido era "único y especial" (línea 30), valores que traspasaron a su descendencia.

El posicionamiento sobre 'la lengua mapuche' constituye para los adolescentes una diferenciación importante entre los miembros de su propia etnia. Quienes hablan la lengua son percibidos como 'más' mapuches, principalmente los de mayor edad en la familia, constituyéndose en un referente cultural para los más jóvenes; en tanto quienes no hablan el idioma son categorizados como 'menos mapuches'. La joven CJ de Temuco define a su abuela y tía como 'hablantes' de la lengua (líneas 98-102) atribuyéndoles un estatus superior pues la joven y sus hermanos recurrían a su padre o tía para saber qué había querido decir la abuela. CJ al no hablar ni comprender el idioma (líneas 101-102) se posiciona con un estatus pasivo al interior de su familia sin posibilidades de interactuar con sus parientes en la lengua de la cultura (líneas 105107). Nótese la descripción vívida del relato mediante la reproducción de discurso directo (líneas 100-102, 106).

94. E: $\quad$ ya (.) y::: por ejemplo allá no se poh tu abuela ¿tu abuela es

95. mapuche?

96. CJ sí, tiene los dos apellidos mapuche 
96. E: ya y ella::: no se puh ¿te ha dicho algo a ti en relación a la cultura?

$97 . \quad$ ¿te ha enseñado algunas cosas?

98. CJ: $\quad$ si, (ja, ja) igual como que de repente cuando va a la casa cuando

99. nosotros estamos acostados, porque nos levantamos tarde a veces

100. (ja, ja) y nos dice ‘ $j a h$, estas niñas! y nos dice y nos empieza a

101. decir cosas mapuche, palabras mapuches y nosotras como ‘quué

102. nos dijo?' le preguntamos a mi tía, que mi tía habla mapuche también

103. E: уa:::

104. CJ: y ella como que siempre igual como que de repente nos reta

105. así cosas en mapuche y uno no cacha mucho (ja, ja) y yo

106. de repente le digo a mi papá ‘¿papá, qué me dijo?’ (ja, ja) porque

107. igual no entiendo mucho.

RS de Santiago tampoco habla ni entiende la lengua mapuche categorizándola como "extraña" (línea 89) lo que respalda con la metáfora "quedábamos pa' adentro" como recurso emocional (línea 99) cuando su abuela le hablaba en mapudungun.

86. E: ¿y de las organizaciones que tú has escuchado, de Carolina, qué es

87. lo que más te llama la atención, porque ella participa en un grupo d

88. de danza no es cierto?

89. RS: sí, las palabras son extrañas, eh::: me gustaría aprender el

90. $\quad$ lenguaje mapuche (.)

91. E: ¿te gustaría?

92. RS: Sí, porque::: eh.::: su manera de hablar, porque yo nunca he

93. escuchado hablar a un Mapuche, así::: un lenguaje de cómo se le

94. puede decir general, que hable formalmente, solamente he

95. escuchado algunas palabras, pero que alguien hable rápido de

96. corrido:::

97. E: de corrido ¿entonces tu abuelita hablaba palabras sueltas?

98. RS: claro, palabras que por ejemplo para decir 'pie' lo decía con una

99. palabra indígena, entonces nosotros quedábamos pa' dentro, no

100. sabíamos que decía, no entendíamos, pero:::es grato tener a 
101. alguien que te de nuestro apellido y aprender su lenguaje sobre

102. $\quad$ todo $($.

103. E: ¿ ¿y eso te gustaría aprenderlo más adelante, cuándo?

104. RS: más adelante, cuando vaya más o menos en tercero medio, es

105. que ahora tengo que subir mis notas porque están muy bajas (.)

106. ya en segundo, tercero ya empiezo, después a los dieciocho ya

107. voy a poder hacer cosas::: de los mapuches, aprender del lenguaje,

108. tal vez hasta aprender danza, que igual es entretenido (.)

RS reconoce que desearía aprender la lengua mapuche, sin embargo relega este deseo para más adelante en el tiempo justificando esta decisión con las bajas notas que posee en el liceo (línea 105). Esta justificación se realiza mediante la estrategia "backtracking"12 argumentando razones que impiden la realización de una acción (se debe poseer la edad adecuada para aprender la cultura mapuche) (líneas 106-103).

La mayoría de los entrevistados posicionan la participación en ritos y ceremoniales mapuches como un requisito fundamental para ser mapuche. Por ejemplo, si retomamos el relato de LS de Temuco quien expresaba ser mapuche 'sólo por el apellido', el joven establece la diferencia entre él y sus abuelos quienes sí se identifican como mapuches (líneas 10-12) porque participan en los guillatunes que se realizan en su comunidad de origen (líneas 14-17), es decir, viajan al campo a participar, en tanto LS no lo hace (línea 19).

1. E: Solamente por tu apellido. Pero ¿tu familia no, no se identifica como

2. familia mapuche?

3. LS: $=$ mi (.) mi tata

4. E: ah::::

5. E: (.) y mi abuela::::

6. E: Ya ¿y en qué sentido se identifican?, ¿participan ellos?

7. LS: Sí, mi tata va a guillatunes, como dijo usted (.) va pa’l

8. campo:::

9. E: ¿YY en qué parte?, de que parte son ellos?

10. LS: Galvarino.

11. E: Ah ya. ¿Y tú no asistes ahí?

12.LS: $\quad{ }^{\circ} \mathrm{No}^{\circ}$ 
RT también de Temuco relata que su identidad y la conexión con la cultura se han ido construyendo en distintos tiempos y espacios culturales, por ejemplo en guillatunes. Es interesante notar cómo ella utiliza variadas estrategias para realzar su relato, como el uso de primera fuente (primera persona), recurso de la memoria (líneas 37-38, 3940), referencia a artefactos culturales como fotografías (línea 40), y descripción vívida de personajes ("guardias", "ramadas", líneas 43-44).

36. E: ¿Tú has participado verdad?

37. RT: Sí desde que tengo:: conciencia, desde que- yo me acuerdo que $>$ la

38. primera vez que fui a un guillatún, tenía como- tres años fue en mi

39. comunidad me acuerdo entre fotos y después el que me acuerdo bien

40. el que me gustó mucho fui a los cinco años mi mamá me llevó, mi

41. mamá a ver tenía como 22 años $>23<$ y me llevó a::: ver ese ese 42 . guillatun, que fue]

42. E: $\quad[y a$

43. RT: fue súper lindo, y fue fue súper::: como se hace, con ramadas,

44. guardias, con todo,

PL de Santiago categoriza su cultura como un espacio donde se viven experiencias muy "lindas" (línea 210) y se posiciona como participante activo en rituales mapuches en su comuna (líneas 209-211). Respalda su argumento mediante las estrategias de corroboración y consenso, es decir, la opinión de terceras personas (no mapuches) que han expresado que les hubiese gustado haber nacido mapuches para disfrutar de los ritos de esa cultura (líneas 208-209).

205. E Ok, oye y ¿algún, no sé, hecho, si se puede decir::: agradable, qué es lo

206. que más rescatas también de ser mapuche?¿cuál sería vendría ser la parte

207. como positiva de ser mapuche?

208. PL: Eh ::: que bastantes personas que no son mapuches me han comentado

209. que a ellos les hubiera gustado ser mapuche y aparte que uno vive cosas

210. lindas, en las ceremonias, en los deportes, con la familia, la organización,

211. el lof, es bonito participar en todo lo que es...lo que convoca lo mapuche. 
212. E: ¿Tú generalmente, participas de los rituales, de costumbres acá en 213. Santiago?

214. PL: Si, yo participo siempre, hace dos semanas, tres semanas me

215. parece, que celebramos, el We Tripantu, estuvimos ahí, celebrando

216. con la machi, con mis primos bailando, haciendo lo que conlleva eso.

El posicionamiento identitario de PL es consistente a lo largo de su conversación con el entrevistador mapuche, y aunque ha experimentado momentos difíciles por su pertenencia a la etnia como haber sido discriminado por sus compañeros en la escuela por su apellido mapuche, mantiene una valoración muy positiva del ser mapuche y de las prácticas culturales de la etnia.

\section{Discusión}

El posicionamiento de los jóvenes respecto del apellido mapuche como indicador esencial de pertenencia étnica se construye discursivamente de dos formas: como proactivo y explícito y como pasivo y menos explícito. Así, CJ de Temuco y RS de Santiago son proactivas y asignan al apellido un carácter esencial de pertenencia. En ambas jóvenes coincide el hecho de que han recibido apoyo y refuerzo cultural de su familia y han mantenido contacto frecuente con sus familiares en sus comunidades de origen. En tanto LS de Temuco se posiciona como sujeto más pasivo y construye un argumento ambiguo respecto de su pertenencia étnica aunque reconoce en sus abuelos una sólida identificación étnica porque participan de las prácticas culturales. También SV de Santiago se posiciona de manera neutral cuidando su imagen frente a su entrevistadora, particularmente respecto del tema de haber vivido en un hogar estudiantil mapuche en Temuco; sin embargo, también declara que mientras residía en Temuco iba constantemente a su comunidad y participaba en las ceremonias culturales.

Ser o no hablante de la lengua mapuche constituye para los jóvenes de ambas ciudades un dilema generacional de alta relevancia, ya que al no poder hablarla ni comprenderla los enmarca en una categoría distinta que sus parientes mapuches más adultos, especialmente quienes residen en las comunidades de origen en el sur. Este dilema lo exteriorizan de variadas maneras, por ejemplo no haber tenido tiempo para aprender la lengua debido a los estudio, a no tener la edad adecuada para aprenderla, o bien porque la consideran una lengua muy difícil.

Por otra parte, la participación activa en ritos y ceremoniales mapuches constituye un elemento central para desarrollar una identidad étnica sólida. Así, RT de Temuco y PL de Santiago concuerdan en evaluar la participación en ceremoniales mapuches como una experiencia muy positiva y que los conecta con su cultura. Ambos declaran ser participantes activos de dichas celebraciones. Este hallazgo coincide con lo relevado 
por Planas (2007) con jóvenes indígenas de Perú en el sentido de que la pertenencia étnica está referida a la comunidad de origen, sin embargo cuando el migrante reside en la ciudad se realiza a través de la recreación de los vínculos comunitarios en el contexto urbano.

Los tres posicionamientos estudiados develan que la construcción identitaria constituye un proceso dilemático donde los jóvenes despliegan discursos que en ocasiones pueden aparecer contradictorios. Ello puede explicarse ya que constantemente deben reconceptualizar su autoadscripción en una tensión que se da entre el apego a los valores tradicionales y la innovación sociocultural que demanda el espacio urbano (Giannelli, 2006). Lo que parece estar a la base de estos procesos dilemáticos es la dualidad entre lo que Verkuyten y de Wolf (2002) conceptualizan como 'ser' y 'sentirse' parte de una etnia, y que explican en términos de autorreconocerse como perteneciente a una determinada etnia y pensar y actuar acorde con las claves culturales del grupo. Así el joven mapuche, al verse enfrentado a evaluar su pertenencia étnica al interior de la sociedad chilena, se mueve discursivamente entre 'ser' y 'sentirse' mapuche. El primero constituye una tarea más manejable para los jóvenes y también menos comprometedora, se puede ser mapuche por poseer el apellido o porque se visita a los parientes más adultos en las comunidades; sin embargo 'sentirse' mapuche involucra otros requisitos de mayor compromiso emocional, social e interaccional. A este respecto Merino y Tileaga (2010) mostraron que los jóvenes mapuches de Temuco y Santiago evidencian en su discurso una tensión implícita entre declarar abiertamente su adscripción étnica y sentirse y actuar como tales y mantener una posición más observante y pasiva respecto de su autoadscripción. Asimismo Cuminao (1998) plantea que la cultura y la identidad mapuche en migrantes mapuches en Santiago se encontrarían en un constante proceso de reformulación y reelaboración de elementos culturales propios pero sin perder la historia que las conecta a un pasado común, ya que no se rompen los vínculos con la comunidad de origen de forma radical, pero que al verse enfrentado a la sociedad moderna el mapuche lo ubica en una situación compleja.

Tanto un posicionamiento más pasivo y distante respecto de la autoidentificación como mapuche como un posicionamiento más explícito y proactivo estarían indicando la presencia del dilema entre el ser y sentirse mapuche, como asimismo su necesidad de transformar y redefinir su identidad, tal como lo señala Aravena (2003), en procesos de construcción, recomposición y adaptación a los imperativos de la sociedad moderna. En definitiva, lo que establecería una diferencia entre ambos tipos de posicionamientos, sin embargo, sería el rol que juegan los adultos en otorgar apoyo y refuerzo cultural a los más jóvenes junto con la mantención de contacto frecuente con sus familiares en las comunidades de origen. 


\section{CONCLUSIONES}

El discurso de los adolescentes mapuches de las ciudades de Temuco y Santiago revela la tensión dilemática que genera su posicionamiento frente a la identificación étnica en contexto urbano. Se trata de un proceso contradictorio de afirmación y negación que opera en una relación dialógica entre la categorización ejercida desde la sociedad chilena no indígena y la autoadscripción a la propia cultura que es minusvalorada por la sociedad mayoritaria. Ello determina en gran medida el dilema que debe manejar el joven entre 'ser' y 'sentirse' mapuche.

Ambos grupos coinciden en posicionarse respecto de su identidad mediante tres rasgos definitorios: poseer el apellido, la lengua mapuche y la participación en ritos culturales, aunque se observan algunas diferencias. El posicionamiento frente al apellido mapuche constituye para los jóvenes de Temuco una acción más dilemática que los jóvenes de Santiago: el apellido constituye por una parte fuente de identidad y compromiso con la cultura, pero al mismo tiempo conlleva limitaciones, como ser discriminado por llevar el apellido o bien utilizarlo como herramienta de acceso a subsidios y becas. Los adolescentes de Santiago en cambio tienden a posicionarse de manera más enfática y atribuyen al apellido un rasgo suficiente para la identificación como mapuche, lo que es más visible en el discurso de las mujeres.

Para los jóvenes de ambas ciudades el manejo de la lengua mapuche otorga estatus diferenciados: a quienes la hablan se les atribuye un estatus 'superior' y a quienes no la manejan un estatus más 'pasivo', estratificando culturalmente a los más jóvenes en un nivel inferior respecto de los adultos y ancianos hablantes.

Respecto de la participación en ritos culturales, ambos grupos coinciden en que ello define la identidad y fortalece el compromiso con la etnia, siendo este rasgo definitorio para los jóvenes de Temuco. En cambio para los adolescentes de Santiago la participación en ceremonias mapuches en sus comunas constituye un acto de re-creación y re-significación simbólica de prácticas que, aunque se desarrollen en espacios culturalmente menos pertinentes, permiten resolver la tensión dilemática del indígena migrante en contextos urbanos apartados geográficamente de las comunidades de origen. Coincidimos con los hallazgos de Planas (2007) en los jóvenes indígenas urbanos del Perú que en la actualidad la etnicidad es vivida de modo distinto por los jóvenes e hijos de migrantes lo que no implica necesariamente una ruptura con la cultura de sus padres.

Finalmente, los vínculos más importantes en los adolescentes mapuches de Temuco y Santiago están centrados en la valoración de sus orígenes cuya motivación inicial nace desde el hogar, y el contacto con las comunidades de origen, sea este ocasional o regular; además de la vigencia y posibilidad de participar en prácticas ceremoniales como el we tripantu o año nuevo mapuche, y el ngillatun en tanto ritual de acción de gracias, conexión con la divinidad. 


\section{REFERENCIAS BIBLIOGRÁFICAS}

Abarca, G. (2002). Mapuches de Santiago. Rupturas y continuidades en la recreación de la cultura. Tesis de magíster, Educación Intercultural Bilingüe, PINS, PROEIB Andes, Plural Editores.

Albó, X. (2005). Ciudadania étnico- cultural en Bolivia. Cuzco: CIPCA.

Antaki, Ch., Billig, M., Edwards, D. \& Potter, J. (2003). Discourse analysis means doing analysis: A critique of six analythic shortcomings. Discourse Analysis Online. [en línea]. Disponible en: http://www.shu.ac.uk/daolprevious/v1/n1/ index.htm)

Aravena, A. (2003). Los Mapuche-Warriache: Procesos migratorios contemporáneos e identidad mapuche urbana. Revista América Indígena, LIX(4), 162-188.

Austin, J. (1961). How to do things with words. Oxford: Clarendon Press.

Baker, P. (1997). Using corpora in discourse analysis. London: British Library Cataloguing in Publication Data.

Baker, C. (2000). Locating culture in action: Membership categorisation in texts and talk. En A. Lee \& C. Poynton (Eds.), Culture and Text: Discourse and Methodology in Social Research and Cultural Studies (pp. 99-113). St Leonards, NSW: Allen \& Unwin.

Bartolomé, M. (1987). Gente de costumbre y gente de razón: Las identidades étnicas en México. México DF: Siglo XXI.

Bascur, C. (1998). La actitud de padres y la orientación de profesores con efecto en la pérdida de la identidad de alumnos mapuches en dos escuelas básicas de Temuco. Tesis de Licenciatura en Educación, Universidad Católica de Temuco, Temuco, Chile.

Bauman, Z. (2000). Identity. Cambridge: Polity Press.

Bengoa, J. (2002). Erosión y transformación de las identidades en Chile. Indiana, 1, $37-57$.

Berger, P. \& Luckmann, T. (1991). La construcción social de la realidad. Buenos Aires: Amorrortu Editores.

Bernal, M., Knight, G., Garza, C., Ocampo, K. \& Cota, M. (1990). The development of ethnic identity in Mexican-American children. Hispanic Journal of Behavioral Sciences, 12(1), 3-24.

Bonfil Batalla, G. (1987). Utopia y revolución. México DF: Editorial Nueva Imagen.

Cantoni, W. (1978). Relaciones del mapuche con la sociedad nacional chilena. Raza y Clase en la Sociedad Postcolonial. UNESCO. Madrid: Organización de las Naciones Unidas para la Educación, la Ciencia y la Cultura.

Censo (2002). Etnias. Censo de la población cbilena. Instituto Nacional de Estadísticas, Gobierno de Chile.

Cerda, A. \& Toledo, M. (2000). La discriminación en la escuela. La visión de los estudiantes. En A. Magendson \& P. Donoso (Eds.), Cuando a uno lo molestan...: Un acercamiento a la discriminación en la escuela (pp. 79-110). PIIE, Santiago de Chile: Lom. 
Cuminao, C. (1998). El gijatun en Santiago: Una forma de reconstrucción de la identidad mapuche. Tesis de magíster, Universidad Academia de Humanismo Cristiano, Santiago, Chile.

Curivil, R. (2007). La fuerza de la religión de la tierra. Una herencia de nuestros antepasados. Santiago: Edición Universidad Católica Silva Henríquez.

Durán, T. (1984). Contacto interétnico chileno mapuche en la IX Región. Cultura, Hombre, Sociedad, 21-52.

Edwards, D. \& Potter, J. (1992). Discursive psychology. Londres: Sage.

Fernández, C. (2006). Mujeres mapuches urbanas de la ciudad de Temuco, autorrepresentación de su identidad al interior de su cultura en la construcción de su historia a partir del paradigma de la diferencia sexual. Tesis conducente al grado de Licenciado en Trabajo Social Mención Desarrollo Social y Políticas Públicas, Universidad de La Frontera, Temuco, Chile.

Foerster, R. \& Montecino, S. (2007). Un gesto implacable guardado en nuestras entrañas: Notas reflexivas sobre una encuesta iluminadora. Centro de Estudios Públicos, 105, 121-141.

Giannelli, L. (2006). Dominios y redes de empleo del mapudungun en el marco rural mapuche. Signos Lingüísticos, 10(5), 99-122.

Gunderman, H. (2006). Comunidades translocales: Grupos y redes sociales indígenas en un contexto de postcomunalidad. Un estudio comparado aymara, atacameño y mapuche. Proyecto Fondecyt 1060973.

Gunderman, H., Vergara, J. \& Foerster, R. (2005). Contar a los indígenas en Chile. Autoadscripción étnica en la experiencia censal de 1992 y 2002. Estudios Atacameños, 30, 91-115.

Hall, S. (2001). Foucault: Power, knowledge and discourse. En M. Wetherell, S. Taylor \& S. Yates (Eds.), Discourse Theory and Practice. A Reader (pp. 72-81). Londres: Sage.

Harré, R. \& van Langenhove, L. (1999). Positioning theory: Moral contexts of intentional action. Oxford: Blackwell Publishers Ltd.

Holstein, J. A. \& Gubrium, J. F. (1995). The active interview. Londres: Sage.

Jefferson, G. (2004). Glossary of transcript symbols with an introduction. En G. Lerner (Ed.), Conversation Analysis: Studies from the First Generation (pp. 13-31). Amsterdam: John Benjamins.

Merino, M., Saiz, J. \& Quilaqueo, D. (2005-2007). Discriminación percibida en el discurso de mapuches y efectos psicosociales: Análisis del discurso de mapuches residentes en Temuco y Santiago. Proyecto FONDECYT 1051047.

Mellor, D., Merino, M. E., Saiz, J. L. \& Quilaqueo, D. (2009). Emotional reactions, coping and long term consequences of perceived discrimination among the mapuche people of Chile. Journal of Community and Applied Social Psychology, 19(6), 473- 491.

Merino, M. E., Mellor, D., Saiz, J. \& Quilaqueo, D. (2009). Perceived discrimination amongst indigenous people in Chile. An application of the Australian taxonomy. Journal of Ethnic and Racial Studies, 32(5), 802-822. 
Merino, M. E. \& Tileaga, C. (2010). The construction of ethnic minority identity: A discursive psychological approach. Discourse and Society, 22(1), 1-16.

Miller, J. \& Glassner, B. (1997). The "Inside" and the "Outside": Finding realities in interviews. En N. K. Denzin \& Y. S. Lincoln (Eds.), Handbook of Qualitative Research (pp. 99-112). Thousand Oaks, CA: Sage.

Montecino, S. \& Willson, A. (1993). Diagnóstico sobre inserción laboral de mujeres mapuches ruralesy urbanas. Universidad de Chile. Facultad de Ciencias Sociales, Programa Interdisciplinario de Estudios de Género. Organización Mundial de la Salud [en línea]. Disponible en: http://www.who.int/child_adolescent_health/es/

Phinney, J. (1990). Ethnic identity in adolescents and adults: Review of research. Psychological Bulletin, 108(3), 499-514.

Planas, M. (2007). Identidad étnica en el Perú: Un estudio cualitativo sobre los discursos de autoidentificación en tres zonas del país. Lima: Universidad Particular Cayetano Heredia.

Potter, J. (1996). Representing reality: Discourse, rhetoric and social construction. Londres: Sage.

Potter, J. \& Wetherell, M. (1987). Discourse and Social Psychology: Beyond attitudes and behaviour. Londres: Sage.

Potter, J. \& Edwards, D. (2001). Discursive social psychology. En W. P. Robinson \& H. Giles (Eds.), The New Handbook of Language and Social Psychology (pp. 103118). Londres: John Wiley \& Sons.

Rapley, T.J. (2001). The art (fullness) of open-ended interviewing: Some considerations on analyzing interviews. Qualitative Research, 1(3), 303-323.

Sacks, H, (1972). An initial investigation of the usability of conversational data for doing Sociology. En D. N. Sudnow (Ed.), Studies in Social Interaction (pp. 31-74). Nueva York: Free Press.

Sacks, H. (1984). Notes on methodology. En J. M. Atkinson \& J. Heritage (Eds.), Structures of Social Action: Studies in Conversational Analysis (pp. 21-37). Cambridge: Cambridge University Press.

Saiz, J. L. (2002). Atribución de estereotipos: Los indígenas mapuches que perciben los chilenos. En J. F. Morales, D. Páez, A. L. Kornblit \& D. Asún (Eds.), Psicología social (pp. 145-151). Buenos Aires: Prentice Hall-Pearson Educación.

Saiz, J. L. \& Gempp, R. (2001). Estudios empíricos sobre la identidad nacional chilena: Revisión y nueva evidencia. En J. M. Salazar (Ed.), Identidades nacionales en América Latina (pp. 219-239). Caracas: Fondo Editorial de Humanidades y Educación, Universidad Central de Venezuela.

Searle, J. R. (1979). Expression and meaning. Cambridge: Cambridge University Press.

Silverman, D. (2001). Interpreting Qualitative Data: Methods for Analysing Talk, Text and Interaction (second edition). Londres: Sage.

Smith, V. (2002). Aportes a la comprensión de la identidad étnica en niños, niñas y adolescentes de grupos étnicos minoritarios. Análisis de Contenido del Discurso. Revista de Ciencias Sociales, 2(96), 71-82.

Tripailaf, D. (1969). Discriminación racial y social crea complejo de inferioridad en el pueblo mapuche. Revista Cauce, VI(46), 4-8. 
Vaughan, G. \& Hogg, M. (2002). Introduction to Social Psychology. Sydney: Prentice Hall. Vergara, J. \& Foerster, R. (2002). Permanencia y transformación del conflicto Estadomapuches en Chile. Revista Austral de Ciencias Sociales, 6, 35-46.

Verkuyten, M. \& de Wolf, A. (2002). Being, feeling and doing: Discourses and ethnic self-definitions among minority group members. Culture and Psychology, 8(4), 371-399.

Wetherell, M. (2009). The identity/Action Relation. En M. Wetherell (Ed.), Theorizing Identities and Social Action (pp. 1-18). Londres: Palgrave MacMillan.

Wetherell, M. \& Potter, J. (1992). Mapping the language of racism: Discourse and the legitimation of exploitation. Londres: Harvester/Wheatsheaf.

Widdicombe, S. \& Wooffitt, R. (1995). The language of youth subcultures: Social identity in action. Hemel Hempstead: Harvester Wheatsheaf.

Wittgenstein, L. (1953). Philosophical investigations. Oxford: Blackwell.

Wooffit, R. (1996). Conversation analysis and discourse analysis. A comparative and critical study. Londres: Sage.

Zimmermanm, D. \& Wieder, D. (1970). The practicalities of rule use. En J. Douglas (Ed.), Understanding Everyday Life (pp. 221-238). Londres: Routledge and Kegan Paul.

\section{NOTAS}

1 Este trabajo presenta avances del proyecto Fondecyt 1090523 (2009-2011) “Construcción discursiva de la identidad étnica en adolescentes mapuches de Temuco y Santiago".

2 A través del proyecto Fondecyt 1051047 (2005-2007) Merino, Quilaqueo y Saiz describieron la percepción de discriminación que manejan los mapuches de Temuco y Santiago y los efectos psicosociales que las prácticas discriminatorias generan en los miembros de dicha cultura.

3 El proyecto Fondecyt 1090523 (2009-2011) se encuentra en su última fase de descripción de los discursos histórico-culturales que están a la base de la construcción identitaria; como asimismo los factores espaciales y territoriales que concurren en la construcción discursiva de la identidad en los adolescentes mapuches urbanos.

4 Potter (1996) describe el stake management como el interés personal que un hablante tiene en un punto de vista o tema donde las descripciones juegan un rol fundamental en la interpretación que el hablante desea que su interlocutor haga de su punto.

5 Según cifras del Censo (2002) del Instituto Nacional de Estadísticas, en Santiago habitan 182.963 mapuches, vale decir un $30.37 \%$ de la población nacional mapuche (604.349). La mayoría, un $33.62 \%$, habita en la región de la Araucanía, correspondiente a 203.221 personas. En el país viven un poco más de 600 mil mapuches, de los cuales casi un 63\% corresponde a población urbana (más de 377 mil personas).

6 Potter (1996) deriva la estrategia category entitlement de los recursos para categorizar la membrecía de Sacks (1984).

7 Este recurso discursivo consiste en presentar un argumento como algo normal, común, del diario vivir, en que el hablante se posiciona como observador y reportador de un evento o 'being ordinary' en palabras del autor.

8 "me molesta que..." constituye un ejemplo del thesaurus emocional de un hablante para describir su posicionamiento respecto de un tema o evento; en tanto "creo que..." constituye un recurso cognitivo. 
9 Se refieren al uso del lenguaje para la construcción de hechos donde el hablante muestra su propia construcción de mundo, por ejemplo "iqué hacerle! las cosas son así en este país".

10 La versión inglesa para esta estrategia es stake inoculation ya que el hablante 'inocula' su argumento preparándose para una postura contrapuesta, de desacuerdo o juicio negativo de parte de su interlocutor. Para mayor detalle de esta estrategia ver capítulos 6 y 7 en Edwards y Potter 1992 y capítulo 5 en Wooffit (1996).

11 La letra 'E' refiere al entrevistador, en tanto las letras 'LS' corresponden a iniciales ficticias otorgadas a los entrevistados (as) para resguardar sus identidades.

12 Backtracking consiste en posicionarse sobre un tema de manera categórica para luego justificar la relativa imposibilidad que el argumento pueda realizarse en los hechos concretos. Esta estrategia hace del argumento una construcción discursiva de tipo circular donde no parece existir una resolución de lo planteado (Antaki, Billig, Edwards \& Potter, 2003). 